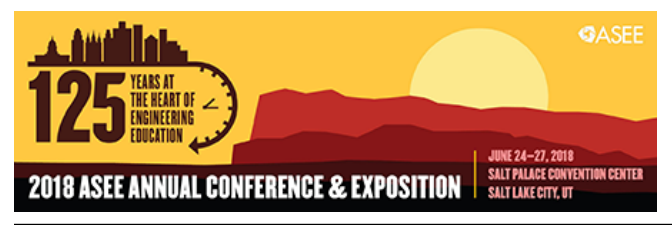

Paper ID \#24535

\title{
International Students' Projects as a Part of Engineering Education
}

\section{Prof. Anna Friesel, Technical University of Denmark}

Anna Friesel is Professor at the Center for Electro-technology, DTU Diplom - Technical University of Denmark, Campus Ballerup. She is also the president of the EAEEIE - European Association for Education in Electrical and Information Engineering, which is a European non-profit organization, with members from nearly seventy European Universities, most of them teaching in the area of Electrical and Information Engineering (EIE). Anna Friesel is a member of the IEEE Educational Activities Board (EAB) Faculty Resources Committee (FRC). The mission of the EAB FRC is "to promote the continued evolution of engineering education and the career enhancement of Engineering, Computing and Technology (ECT) faculty through quality programs/products/services designed to advance innovation in educating engineers". She is an Associated Editor in IEEE Transactions on Education. She collaborates regularly with many technical universities in Europe, Latin America and USA. Her research interests include mathematical modeling, system dynamics, control theory, and educational methods in automation, robotics, and in engineering in general. 


\title{
International Students’ Projects as a Part of Engineering Education
}

\begin{abstract}
This paper summarizes our international activities in the Section for Electrical Technology at the Technical University of Denmark, Center for Bachelor of Engineering Studies (DTU Diplom). Globalization makes it necessary to cooperate on an international platform especially in the fields of engineering and technology. We cooperate with many universities worldwide in order to make it possible for our students and graduates to achieve international competencies, which today are required by many companies. Engineering projects are in many cases teamwork of specialists from many different countries and from different cultures. The ability to work in international teams and with projects involving participants from different countries and cultures may differ greatly depending on the educational traditions of the students' homelands. We describe our international activities with a focus on international students' projects performed in cooperation with technical universities abroad in order to offer the students the possibility to train their international skills. Developing and planning of such activities often gives some more practical challenges, such as differences in how engineering programs are designed, the differences in academic calendars and the amount of credits given for projects and courses in different countries. In some cases, the differences in academic calendars are so big, that it is a major obstacle in arranging common student projects. This paper describes our experience in arranging common activities in spite of the named obstacles. The projects described in this paper are the result of our cooperation with the School of Engineering Technology and School of Aviation and Transportation Technology, Purdue University in USA, and Fontys Mechanical Department, University of Applied Sciences in Eindhoven, Netherlands.
\end{abstract}

\section{Introduction}

The Technical University of Denmark, in Danish: Danmarks Tekniske Universitet (DTU), is the biggest technical university in Denmark. DTU Diplom is a unit under DTU located at the DTU Ballerup Campus, which has all modern facilities and is located in attractive natural surroundings. Engineering education at DTU Diplom includes 17 programs at the level of Bachelor of Engineering (B.Eng). Most of our undergraduates studying engineering courses have, as their goal, to work with practical engineering tasks in an engineering company after graduation. Many companies today work globally and prefer those candidates with abilities and skills to work in international teams with engineers and technicians from other countries and cultures ${ }^{1,2}$. Both the European Union and private organizations support international cooperation between universities in order to increase students' and professors' exchange and mobility internationally ${ }^{3}$. Engineers in global companies must be able to operate in a team-based, multidisciplinary world where communication in English and international skills are very important. Working on projects in teams has been a part of engineering education for several years, and this is a common practice in many 
universities ${ }^{4,5,6}$. Project based learning and teamwork in engineering education tends to increase students' motivation and give them a sense of practical experience ${ }^{7}$. Combining engineering projects with international teamwork significantly contributes to develop students' international skills ${ }^{8,9}$ including communication skills in a foreign language, especially in English.

In order to prepare our students for their future work in international companies, we included the activities, which train them to:

- communicate effectively, orally and in written form in English;

- function effectively in international teams;

- interact with and collaborate on a real-world project with students from a different culture and nationality;

- schedule the project activities to successful solution;

- include all requirements from the project's provider to final proof of concept;

- analyse, synthesize, integrate and apply technical engineering knowledge into a real worldengineering project;

- apply creativity and innovation in the design of system's solution;

- accomplish self-study of new knowledge necessary to find the solution for the project.

\section{Common students' projects}

In order to carry out engineering projects with students from different countries and cultures, we established cooperation with the School of Engineering Technology and School of Aviation and Transportation Technology, Purdue University in USA, and Fontys Mechanical Department, University of Applied Sciences in Eindhoven, Netherlands. The projects students worked on were three very different projects:

1. "Real-world" engineering project provided by an international company with branches in Denmark and in USA, involving a company advisor as a supervisor for students and university supervisors.

2. Project stated by School of Aviation, Purdue, concerning modernization, digitalization and visualization of an aircraft engine test.

3. Innovation project formulated by students, which has as a goal to develop a new product with potential to start a company for production of this product.

All projects were founded by respective universities, but in the future, we will apply for founding from the involved companies and we will investigate other possibilities for funding.

At DTU Diplom all projects were assessed in final oral examination. It is required according to our study programs for this kind of activities - project based courses. The examination is based on the final report, team presentation, discussion of the project work and the results, and individual questioning of all team members. The grading is based on a general impression of the level achieved by each student relative to the objective of the course and the project. The supervisor and another professor from DTU Diplom perform the examination. It is according to Danish rules for 
examinations, which require additionally an external examiner (from other university or from company) or internal examiner (from the same university).

\section{Project 1}

This project was developed and completed by a joint international team consisting of students from Purdue University, USA and students from DTU Diplom, Denmark. The project was a senior capstone project for Purdue students and an Innovation Pilot course/project (compulsory course at 5-th semester ${ }^{10}$ for DTU Diplom students).

The team consisted of:

- Two students (one female and one male) from Manufacturing Engineering Technology, Purdue;

- $\quad$ One student (female) from Electrical Engineering Technology , Purdue;

- $\quad$ Three students (males) from Electrical Energy Technology, DTU Diplom;

- $\quad$ One student (male) from Electrical Engineering, DTU Diplom.

This international team worked to create a solution to the project provided by a company and was supervised by faculty members from their respective universities, together with a company advisor, who was a manager in the Research and Development Sector of the company branch in Denmark. His responsibility was to provide the team with information regarding the technical details and determine if the results were beneficial to the company. Student team members were held to standards that were defined by the students and focused on accountability, communication and task roles. The team appointed one student from DTU and one student from Purdue to be responsible for keeping deadlines and assigned tasks for the project.

Communication was frequent and responsive, the students used emails which were forwarded to all members of both universities. Faculty mentors held weekly meetings with their university's students to assist them with their weekly action items. Weekly meetings hosted between the teams of Purdue University and DTU were also attended by both faculty mentors. This allowed them to observe the communication and work with the students, as well as allowed them to comment on issues they saw as problematic or potential obstacles. The company advisor was mostly attending the named meetings too, and provided the students with the necessary information regarding the project.

The first face-to-face meeting between Danish and American students took place at Purdue University five weeks after the start of the project. DTU students arrived at Purdue together with their faculty supervisor. The students were working together for a week, including a visit to the USA's branch of the company. Different cultural and social activities have been arranged for Danish and American students by the Purdue faculty supervisor, also including attending the College football. DTU students also attended some classes at Purdue, in order to get an impression on how the teaching is similar or different from the teaching in their home university. The American team members hosted the DTU students which made it easier for the students during the whole project to communicate and understand each other. 
The second face-to face meeting was at the very end of the project, when Purdue students visited DTU students and made the final presentation of the project at the company site in Denmark. In Denmark, Purdue students were hosted by their Danish teammates, who also arranged several cultural and sightseeing activities to give the American students more knowledge about Denmark.

The overall goals for this project, for both Danish and American students, were:

- $\quad$ To train their communication skills orally and in written form;

- $\quad$ To function effectively in international teams;

- To interact with and collaborate on a real-world project with students from a different culture/nationality;

- To train how to schedule together the project activities;

- To accomplish self-study of new knowledge necessary to find the solution for the project.

However, there were also some challenges during the project and the most important were:

- Differences in expectations and requirements to the students' results and performance from the universities in Denmark and in USA;

- The communication problems according to time differences combined with other activities and courses students have had;

- This was a two-semester project and DTU students have been taking their internship during the second semester of the project. This caused even more problems with communication and the workload used on the project by DTU students, because the internship in a company in Denmark requires full days of work, five days a week.

The students at both universities worked hard with the project. However, difficulties like communication problems, program differences at DTU and Purdue, responsibilities to study other subjects combined with the Danish students' internship were the reasons that the final result of this project was not as successful as expected from the beginning.

\section{Project 2}

This project was quite different from Project 1. The main purpose of Project 2 was to expose the students from different academic programs and cultures to interdisciplinary work and to gain experience with teamwork in an international setting, which is crucial in a highly globalized world. During the project work, DTU and Purdue students had the focus on project management, project planning, process improvement and communication between two parts of the team, because of their different backgrounds, both in an academic and a cultural sense. In technical aspects of this project, students were focusing on putting together a technically robust solution for the actual problem they had to solve together. It was the goal of this project to hand over a working application for engine test when running checks on a PT-6 engine at Purdue's Aviation laboratory. The result of this project will make it easier for Purdue students and teachers to make their tests and experiments and also give them the opportunity for further development of the designed application if needed. 
Participants in this project were:

- 3 male 5-th semester students from DTU, IT Electronics study program;

- 3 male 8-th semester students from Purdue, Aeronautical Engineering Technology program.

Faculty members from their respective universities mentored this international team.

The first and the only face-to-face meeting took place rather late, which was six weeks after the beginning of the project, when DTU students came to Purdue on a five day visit. The visit took place so late, because we had difficulties to find an appropriate date for the visit, such that it did not interfere with other courses, holidays or semester breaks at both universities. That is why the students realized the necessity to establish sound lines of communication between two parts of the team from the beginning of the project, and to establish who is mainly responsible for the communication between these parties. It was an essential part of the plan for the development of the project. The obvious choice for communication was to use email as the main line of communication and within the first few days of the project all students were convinced that this was the best way to communicate. However, this soon led to various complications, which in the opinion of students were following:

- $\quad$ Communication via email slows the process of exchanging information. It took on average 56 days for each team to respond to a request. This had an adverse effect for both teams, it inhibited the efficiency of the development process (e.g. building the requirement specification) and it served as a source of frustration between both teams, leading to potential conflicts.

- Communication in a project running for only 13 weeks (duration of one semester at DTU) require fast feedback, utilization of natural (spoken) language and enables sender and recipient to communicate in a personal manner. These are the elements which email clearly lacks.

On the other hand, communicating via email had positive effects such as:

- Email enables a sender to communicate with many at once; it is a parallel form of communication, which the teams utilized to their advantage. One sender could inform all parties (also external interest groups, like professors and other advisors) of what was going on.

- Email serves as an implicit way of documenting the process. Writing emails to one another can, if used correctly, serve as a way of documenting the process from beginning until the end.

Communicating via email did have its challenges, but taking both advantages and disadvantages into account, it was the easiest way to communicate for Danish and American students working with this project, from locations placed on two continents, and being apart with a time difference of six hours. After some time both groups, independently of each other, wanted to switch to a more dynamic way of communicating, i.e. combining email, video conferencing and instant messaging. Six weeks after the beginning of the project, DTU students went to visit the Purdue students and 
already the first meeting was a landmark in terms of elevating the efficiency in development of the project. The meeting was very important in order to create a feeling of togetherness between two groups with no prior knowledge or relationship with one another. One day after arrival, DTU students were invited to watch college football and to have lunch at homes of Purdue students. Both events had a huge effect on the way both groups started to interact with one another. Studies show $^{8}$ that fundamental assumptions in terms of interpersonal norms and values between members of a group are important if forming a bond should be successful, and these norms and values can be strengthened through socialization.

The technical scope of the project, which was to digitalize a check list managed by students at Purdue University when operating the PT-6 engine, has been accomplished. A mobile application has been developed to run on an Android device. Purdue's students and teachers can now utilize this mobile application when performing a run procedure as a digital assistant. With the mobile application in hand, students can get detailed instructions on how to perform the engine check, accompanied by pictures and as an option for further assistance.

This interdisciplinary and international cooperation has resulted in a working model, ready to be used by students and teachers at Aviation Department at Purdue, and both universities continues their cooperation with similar projects.

\section{Project 3.}

The main goal of this project was, like with the two previously described projects, to train students from two universities, DTU and Fontys, to work in interdisciplinary and multicultural teams ${ }^{11}$. On the other hand, this project was quite different from the other two, because the students were asked to create their own product. They were asked to design, calculate and perform a prototype of an innovative product, which could be a basis of a new start-up company and, if possible, be patentable.

The project participants were:

- 3 male students from DTU, IT Electronics program;

- 1 male student from DTU, Software Technology program;

- 4 male students from Fontys, Mechanical Engineering program;

- 2 female students from Fontys, International Marketing Management program.

As with the other projects, communication the first 5-6 weeks was based on emails and Skype meetings. There is no time difference between Denmark and the Netherlands, so it was not a problem to agree on time for Skype meetings. However, there were some communication issues in the beginning because:

- English is not the native language for all participating students;

- there were all together 10 students communicating in a single meeting by Skype, which does not give a single student much "space" to express his/her opinion; 
- $\quad$ students needed to find and agree to work on a completely new product and this was a biggest challenge for students from four different disciplines (electronics, software, mechanical engineering and marketing).

The idea for the project was at first formed after about 5 weeks after the start of the semester, and the first face-to face meeting was arranged 7 weeks after the start of the project, when DTU students went to Fontys. DTU students met the Fontys' students at the main campus of Fontys and already after the first hour of the meeting, the idea for the common product was formed. The obstacles in communication observed during the Skype meetings were gone and students could communicate without any problems and discuss the details of their common project. The students discussed the main tasks to be performed, the schedule for the work to be done and they appointed the responsible students at both universities for each task. The foundation for the new invented product has been established. Communication in English was not easy even during the visit, because the students had a different basic knowledge of professional English expressions. The students from Mechanical program did not have experience with English expressions used in Electronics and vice versa. However, it did not cause significant problems with their project work. Concerning the differences in culture and customs, the students concluded that there is a minimal or even no difference at all, between Denmark and the Netherlands. Another visit, when Fontys' students came to visit DTU students, took place after the end of the semester. All team members presented the results of their project at the final meeting at DTU, and the students could show the first model of their invention. The designed model shows the principal function of their invention, although there are some missing functions, which needed improvement. The students pointed out during the presentation of their project that the main goal of the project was achieved, and it was to learn how to work with interdisciplinary projects in international teams.

\section{Conclusion}

The effects of the three projects described above are valuable for our understanding of the dynamics of interdisciplinary and international teamwork in engineering education and in engineering in general. The thread of consistency for educators is to train the engineering students for their future work in global companies:

- to work in international and interdisciplinary teams with engineering projects;

- to establish personal connections with all project's participants in order to create a solid background for common goals in the project;

- to find a communication method which will support the existing conditions for the project team, including time difference, geographical distance, different culture and customs, language problems and other barriers;

- to adapt team members' and supervisors' expectations according to different requirements at different universities; 
- to take responsibility for their actions and teach them that each individual member of the team creates a positive impact on the result of the project.

This will lead to better, more honest and thereby more efficient project completion, which at the end of the day will lead to a greater potential for succeeding with the project.

We continue our cooperation with Purdue and Fontys universities and we plan to extend the international cooperation to include two more universities in the future. The next step is to establish cooperation in order to give the students the possibility to complete their internship abroad.

\section{Acknowledgment}

I would like to thank the professors Phillip Sanger and Sergey Dubikovsky from Purdue, and professor Hay Geraedts from Fontys, for our good discussions, close cooperation and great support for students during the projects. Thanks to all the students for valuable discussions on future development of international projects and cooperation, and special thanks to professor David Ashworth (DTU Diplom) for his comments concerning this paper.

\section{Bibliography}

1. Tranter, I.,Brown, F., "A synergy of cultures - the place of multidisciplinary teams in final year undergraduate design projects”, Proceedings of the Second International Symposium in Engineering Education, 1994.

2. Friesel A., "Improving the Engineering Competencies in Education with Multi-Disciplinary Design Projects", International Conference on Engineering Education, July 25-29, 2005, Gliwice, Poland.

3. Ashworth,D., Friesel,A., "Preparing students for engineering tasks in industry - working in international teams with projects”, Proceedings of the 37 $7^{\text {th }}$ SEFI Annual Conference 2009, Rotterdam, Netherlands, July 1-4, 2009.

4. Andersen, A. "Implementation of engineering product design using international student teamwork - to comply with future needs”, European Journal of Engineering Education, 2001, Vol. 26, No. 2, pp. 179-186.

5. Fink, F.K., "Integration of Work Based Learning in Engineering Education", $31^{\text {st }}$ ASEE/IEEE Frontiers in Education Conference, October, 2001.

6. Larson, E.C. and La Fasto, F., “Team Work”, McGraw-Hill, New York, 1989.

7. Friesel,A. "Engineering education resulting in skilled, inventive and innovative professionals, how?", CDIO Conference (Engineering Leadership and Innovation), 9-13 June 2013, Cambridge, MA, USA.

8. Sheppard,K., Dominic,P., Aronson,Z., "Preparing Engineering Students for the New Business Paradigm of International Teamwork and Global Orientation”, Proceedings: Enhancement of the Global Perspective for Engineering Students by Providing an International Experience, Engineering Conferences International Year 2003, April 6-11, 2003; Tomar, Portugal

9. Schadewitz,N., Norhayati,Z., "Cross-cultural collaboration Wiki: evolving knowledge about international teamwork”, IWIC’09, Proceedings of the 2009 international workshop on Intercultural collaboration, Palo Alto, California, USA — February 20 - 21, 2009

10. Innovation Pilot- course description: http://kurser.dtu.dk/course/62999

11. Geraedts,HGM., Päätalo,H.,"International collaboration in engineering projects on product innovation”,. 41-st SEFI Conference, 16-20 September 2013, Leuven, Belgium. 